\title{
Gender and Sexual Orientation Bullying Victimization are Associated with Gun Carrying Among Adolescent Boys
}

\author{
Kyle T. Ganson ${ }^{1}$ D . Jason M. Nagata ${ }^{2}$ D
}

Published online: 4 August 2020

(c) Springer Science+Business Media, LLC, part of Springer Nature 2020

\begin{abstract}
Gun carrying and bullying victimization are associated among adolescent boys, however the type of the bullying remains relatively unknown. This study aimed to identify whether experiencing bullying victimization based on gender and sexual orientation is associated with carrying a gun to school among adolescent boys. A cross-sectional analysis among a representative sample of high school boys $(n=3672)$ from the 2015 Maine Integrated Youth Health Survey was conducted. Odds ratios (OR) and 95\% confidence intervals (CI) were obtained using logistic regression analyses while controlling for grade level, race/ethnicity, sexual orientation, suicidal ideation, alcohol and marijuana use, and gun access. Among the sample, $3.3 \%$ reported carrying a gun to school at least one time in the previous 12-months, $9.5 \%$ reported experiencing gender-based bullying victimization, and 7\% reported experiencing sexual orientation-based bullying victimization. Regression analyses indicated that adolescent boys who experienced gender-based bullying victimization (OR 3.40, 95\% CI 1.64, 5.62, $p<.001$ ) or sexual orientation-based bullying victimization (OR 3.57, 95\% CI 1.91, 6.67, $p<.001$ ) had greater odds of reporting they carried a gun to school while controlling for grade level, race/ethnicity, sexual orientation, suicidal ideation, alcohol and marijuana use, and gun access. These results expand upon previous gun carrying and bullying research by identifying the specific type of the bullying experienced and have important implications for social workers and school personnel. Importantly, these results emphasize the need to address two of the Grand Challenges for Social Work: building healthy relationships to end violence and ensuring the healthy development for all youth.
\end{abstract}

Keywords Adolescent boys $\cdot$ Gun carrying $\cdot$ High school $\cdot$ Bullying $\cdot$ Sexual orientation $\cdot$ Gender norms

Gun carrying among adolescents presents a significant problem for social workers, school personnel, policymakers, and parents. Firearms deaths were the leading cause of injury-related deaths for adolescents aged 10-19 in 2017 in the United States, including 1793 homicides, 1295 suicides, and 69 unintentional deaths (CDC, 2019). Despite these statistics, gun carrying among adolescents often gains public attention and concern via school shootings. Between 2013 and 2015, there was an almost two-fold increase in school shootings in the United States (Kalesan et al., 2017). Social workers may play an important role in early identification

Kyle T. Ganson

kyle.ganson@utoronto.ca

1 Factor-Inwentash Faculty of Social Work, University of Toronto, Toronto, ON, Canada

2 Division of Adolescent and Young Adult Medicine, Department of Pediatrics, University of California, San Francisco, San Francisco, CA, USA and intervention of potentially violent situations, risk assessments of students who are more likely to perpetrate gun violence, and crisis intervention (Johnson \& Barsky, 2020). However, identifying factors associated with carrying a gun to school is needed and this knowledge may help develop important prevention and intervention strategies to prevent future school gun-associated violence.

Developing knowledge on gun carrying on school grounds remains a current challenge, which is in part due to gun carrying as a measure being conflated with other weapons (e.g. knives, clubs, etc.), particularly as it relates to bullying and weapon carrying at school (Valdebenito, Ttofi, Eisner, \& Gaffney, 2017). This measurement issue reduces the ability to identify specific predictors of gun carrying exclusively. In 2017 , nearly $16 \%$ of adolescent high school students carried a weapon (e.g. gun, knife, or club) at least one time in the previous 30 days, while nearly $4 \%$ carried a weapon on school property (Kann et al., 2018). Evidence continues to suggest that high school boys $(6 \%)$ have three 
times the prevalence rate of weapon carrying on school property compared to high school girls (2\%). Similarly, fewer than $2 \%$ of high school girls report gun carrying compared to nearly $8 \%$ of high school boys (Kann et al., 2018). These data highlight the disproportionate rates of weapon carrying between adolescent boys and girls.

Between the years 2002 to 2013, handgun carrying among White adolescent boys increased from nearly 3\% to over 4\% (Vaughn, Nelson, Salas-Wright, DeLisi, \& Qian, 2016). In that time, the prevalence rates of handgun carrying among adolescent boys was higher among high school aged (15-17 years) boys compared to middle school aged (12-14 years) boys (Vaughn et al., 2016). This situation is concerning given that adolescent boys accounted for $88 \%$ of all injury-related firearm deaths among adolescents aged 10-19 in 2017 (CDC, 2019). Furthermore, research continues to suggest that perpetrators of shootings at schools are overwhelming male (Fox \& DeLateur, 2014). It appears that adolescent boys are at particular risk of both gun and weapon carrying on and off school grounds, as well as firearm-related injury and death. More research is needed to focus solely on this population to identify associated risk factors of gun carrying, specifically as it relates to gun carrying on school grounds and bullying victimization.

In general, bullying encompasses verbal, physical, or relational behaviors that are aggressive and intended to harm the victim (Menesini \& Salmivalli, 2017). Involvement in traditional bullying (35\%) and cyberbullying (15\%) is relatively common among adolescents (Modecki, Minchin, Harbaugh, Guerra, \& Runions, 2014). In particular, adolescent boys are often more likely to perpetrate and become victims of bullying compared to adolescent girls (Carlyle \& Steinman, 2007).

Bullying has been identified as an associated risk factor for weapon carrying, including gun carrying, among adolescents (Valdebenito et al., 2017; van Geel, Vedder, \& Tanilon, 2014). In the United States, multiple studies have shown that adolescent victims of bullying were more likely to carry a weapon at school (Esselmont, 2014; Pham, Schapiro, John, \& Adesman, 2017; Schapiro, John, \& Adesman, 2014). Interestingly, being the perpetrator of bullying also increases the risk of weapon carrying (Dukes, Stein, \& Zane, 2010; Valdebenito et al., 2017; Van Geel et al., 2014). What remains relatively unknown is the type of the bullying that leads to gun and weapon carrying among victims.

Two types of bullying that warrant investigation are bullying based on gender and bullying based on sexual orientation. Bullying based on gender is defined as "threatening and harassing behaviors based on gender or the enforcement of gender-role expectations" (Anagnostopoulos, Buchanan, Pereira, \& Lichty, 2009, p. 520). Bullying based on sexual orientation encompasses harassment that is homophobic in nature (Birkett, Espelage, \& Koenig, 2009; Birkett \&
Espelage, 2015). Bullying victimization based on both gender and sexual orientation has negative outcomes among adolescents, such as depression and diminished school belonging (Collier, Van Beusekom, Bos, \& Sandfort, 2013). In a small sample of adolescent boys, researchers found that participants who experienced bullying victimization based on perceived sexual orientation (e.g. bullying because perpetrators believed victims were gay) were more likely to experience psychological distress and poor perceptions of their schooling (Swearer, Turner, Givens, \& Pollack, 2008). This research shows the negative impact bullying victimization based on gender and sexual orientation has on adolescent boys' social and mental health.

Research has identified several correlated factors that are associated with both gun carrying and bullying. These include gun access, mental health symptoms, including suicidal ideation, and substance use. Adolescents are adept at accessing guns (Brown, 2004) and adolescent boys often have greater access to guns compared to adolescent girls (Wilkinson \& Fagan, 2001). Access to a gun is particularly concerning for adolescents, as gun access can increase the risk of suicide among adolescents (Brent et al., 1991; Grossman et al., 2005). Given that bullying victims often experience significant mental health effects, including anxiety, depression, and suicidal ideation (Arseneault, Bowes, \& Shakoor, 2010), as well as substance use (Carlyle \& Steinman, 2007), reducing gun access is imperative to protect against potential self-harm. Furthermore, among high school boys, substance use, depression, and suicidal ideation are associated with weapon carrying, including gun carrying, on school property (Muula, Rudatsikira, \& Siziya, 2008). Most concerning, research conducted by Romero, Bauman, Ritter, and Anand (2017) showed that high school adolescents who carried a gun in the previous 30 days were more likely to attempt suicide. It is clear that there are overlapping and complex relationships between gun and weapon carrying, bullying victimization, and multiple negative mental health and substance use outcomes that may hinder the positive development of adolescent boys. This further warrants research to provide adequate knowledge for social work practitioners.

\section{Theoretical Perspective, Research Aim, and Hypotheses}

The negative mental health outcomes associated with bullying victimization may lead to significant risky behaviors, including gun carrying on school grounds. The "vulnerability/self-protection hypothesis" posits that adolescent bullying victims turn to gun or weapon carrying as a means of self-protection from the repetitive and imbalanced power dynamic experienced via bullying (Valdebenito et al., 2017, 
p. 63). This theory is supported by empirical research indicating that being a victim of bullying is a significant predictor of gun carrying among adolescents (Valdebenito et al., 2017; Van Geel et al., 2014). To date, measurement of bullying victimization among adolescents has been inconsistent. The specific type of bullying measures often focus on general teasing, making fun, and embarrassing, as well as physical acts and name calling, with fewer measures investigating sexual harassment and homophobic teasing (Vivolo-Kantor, Martell, Holland, \& Westby, 2014). Thus, there remains a lack of knowledge on the specific type of bullying victimization, such as bullying based on gender and sexual orientation, and associations with gun carrying. This leaves a gap in knowledge for social work practitioners, particularly those in school settings, who are on the front lines of addressing mental health symptoms, substance use problems, interpersonal conflicts (e.g. bullying), and risk-taking behaviors (e.g. gun carrying) among young people.

In this study, we aimed to gain an understanding of the type of bullying victims experience that may increase the odds of carrying a gun to school. We hypothesize: 1. High school boys who experience bullying victimization based on gender will have increased odds of reporting they carried a gun to school compared to boys who do not experience bullying victimization based on gender; 2 . High school boys who experience bullying victimization based on sexual orientation will have increased odds of reporting they carried a gun to school compared to boys who do not experience bullying victimization based on sexual orientation. Given the "vulnerability/self-protection hypothesis", we posit that high school boys who experience these unique types of bullying victimization will resort to carrying a gun to school as a means of self-protection.

\section{Methods}

In this study, we analyzed the 2015 Maine Integrated Youth Health Survey (MIYHS). The MIYHS is representative of the state of Maine and is conducted biannually by the Maine Department of Education and the Maine Department of Health and Human Services to gather data on a wide range of health topics concerning youth. While the MIYHS also surveys elementary and middle school students, this analysis only includes high school students. We focused on high school students given the previous research indicating higher prevalence of handgun carrying among high school boys (Vaughn et al., 2016). Further, research has shown that school shooters over the last 19 years were of high school age and the majority of school shootings in that time occurred at high schools (Livingston, Rossheim, \& Hall, 2019). The 2015 MIYHS sampled all 132 high schools in Maine, with 112 high schools participating. There was a total of 48,929 students enrolled in the participating high schools, with 38,314 students participating in the survey (78.3\% response rate). This analysis included only participants who identified their sex as "male" given the research linking gun carrying (Kann et al., 2018; Vaughn et al., 2016) and bullying (Carlyle \& Steinman, 2007) among adolescent boys, thus resulting in a sample of 19,171 participants. Due to the module-based survey design of the MIYHS, only 4729 participants were asked the gun carrying measure, representing the final analytic sample. The MIYHS is administered during school hours and consent is gathered from parents or guardians via a passive, opt-out consent procedure by the Maine Department of Health and Human Services. The authors did not participate in data collection. See the Maine Department of Health and Human Services for more information on the MIYHS (Maine Department of Health and Human Services, 2019). This study was approved by the Simmons University Institutional Review Board.

\section{Measures}

The 2015 MIYHS questions were adapted from various surveys. This includes: The Youth Risk Behavior Survey, The Maine Youth Drug and Alcohol Use Survey, The Youth Tobacco Survey, The Search Institute's Developmental Assets Profile, and The Maine Child Health Survey, among others. The validity of the MIYHS and the measures under study are unknown.

\section{Dependent Variable}

Gun carrying was measured using the question, "How many times in the past year (12 months) have you taken a gun to school?" Responses included, "0 times", "1 time", "2 or 3 times", " 4 or 5 times", 6 or 7 times", 8 or 9 times", " 10 or 11 times", and " 12 or more times". Responses were dichotomized to 0 times (0) and $\geq 1$ time (1). This aligns with protocols of previous analyses (Esselmont, 2014; Pham et al., 2017; Vaughn et al., 2012).

\section{Independent Variables}

Gender-based bullying was measured using the question, "Has anyone ever made offensive comments or attacked you at school or on your way to or from school because of how masculine or feminine you are (that is, acting 'too much like a girl' if you are a boy, or acting 'too much like a boy' if you are a girl)?" Responses included, "No" (0) or "Yes" (1).

Sexual orientation-based bullying was measured using the question, "Has anyone ever made offensive comments or attacked you because of your perceived sexual orientation at school or on your way to or from school?" Responses included, "No" (0) or "Yes" (1). 
Both independent variables were modified from the 2015 Centers for Disease Control and Prevention's (CDC) Youth Risk Behavior Survey (YRBS) optional measures (CDC, 2015).

\section{Covariates}

Alcohol use was measured using the question, "During the past 30 days, on how many days did you have at least one drink of alcohol?" Responses included, "0 days", "1 or 2 days", "3 to 5 days", "6 to 9 days", "10 to 19 days", "20 to 29 days", and "All 30 days". Responses were dichotomized to 0 days ( 0 ) and $\geq 1$ day (1).

Marijuana use was measured using the question, "During the past 30 days, how many times did you use marijuana?" Responses included, " 0 times", " 1 or 2 times" "3 to 9 times", "10 to 19 times", "20 to 39 times", and "40 or more times". Responses were dichotomized to 0 times (0) and $\geq 1$ time (1).

Suicidal ideation was measured using the question, "During the past 12 months, did you ever seriously consider attempting suicide?" Responses included, "No" (0) or "Yes" (1).

Gun access was measured using the question, "If you wanted to get a gun, how easy would it be for you to get one?" Responses included, "Very hard", "Sort of hard", "Sort of easy", and "Very easy". Responses were dichotomized to "Hard (very hard \& sort of hard)" (0) and "Easy (very easy \& sort of easy)" (1).

\section{Demographic Variables}

Grade was measured using the question, "In what grade are you?" Responses included, "9th grade" (0), "10th grade" (1), "11th grade" (2), and "12th grade" (3).

Racelethnicity was based on self-report categories, with response choices including, "White" $(0)$, "Hispanic" (1), "Black" (2), "Asian" (3), "American Indian/Alaskan Native" (4), "Native Hawaiian/Pacific Islander" (5), and "Multiple races" (6). Due to small cell sizes, "American Indian/Alaskan Native" and "Native Hawaiian/Pacific Islander" were combined with "Multiple races" to create an "Other race/ethnicity" category.

Sexual orientation was measured using the question, "Which of the following best describes you?" Responses included, "Heterosexual (Straight)", "Gay or Lesbian", "Bisexual", or "Not sure". Responses were recoded to "Heterosexual (Straight)" (0), "Sexual minority" (gay and bisexual; (1), or "Not sure" (2).

\section{Statistical Analysis}

Data analysis was conducted in 2019 using STATA 15.1 (StataCorp, 2017). The MIYHS's pre-constructed sample weights were applied to provide a state-wide representative sample. Univariate analysis was conducted to gather a descriptive overview of the data. Chi-square tests were used to assess the association between gun carrying and the independent variables, covariates, and demographic variables. Logistic regression analyses were used to examine the relationship between gender- and sexual orientation-based bullying and carrying a gun to school while controlling for the demographic variables and covariates. Significance level for bivariate and multivariate analyses was set at $\alpha=0.05$.

\section{Results}

Among the sample, 3.3\% $(n=176)$ reported that they carried a gun to school one or more times in the past year. Nearly $9.5 \%(n=439)$ of participants reported experiencing bullying victimization based on gender and 7\% $(n=339)$ reported experiencing bullying victimization based on sexual orientation. Results from Chi-square tests indicated that there are statistically significant associations between carrying a gun to school one or more times in the past year and gender-based bullying $\left(\chi^{2}=65.41, p<.001\right)$, sexual orientation-based bullying $\left(\chi^{2}=82.12, p<.001\right)$, and gun access $\left(\chi^{2}=60.32, p<.001\right)$. With the exception of grade level, all other variables were significantly associated in bivariate analysis. Table 1 presents univariate and bivariate results.

Table 2 presents the odds ratios and $95 \%$ confidence intervals of the logistic regression analyses. Our first hypothesis that high school boys who experience bullying victimization based on gender will have increased odds of reporting they carried a gun to school compared to boys who do not experience bullying victimization based on gender was supported based on the results from Model 1. Results showed that adolescent boys who experienced bullying victimization based on gender, compared to those who did not, had significantly greater odds of reporting they carried a gun to school one or more times in the past year (OR 3.40, 95\% CI 1.64, 5.62, $p<.001$ ) while controlling for grade level, race/ethnicity, sexual orientation, suicidal ideation, alcohol and marijuana use, and gun access. Similarly, our second hypothesis that high school boys who experience bullying victimization based on sexual orientation will have increased odds of reporting they carried a gun to school compared to boys who do not experience bullying victimization based on sexual orientation was supported based on the results from Model 2. Results showed that adolescent boys who experienced bullying victimization based on 
Table 1 Weighted descriptive and bivariate analyses from the 2015 Maine Integrated Youth Health Survey $(n=4,729)$

\begin{tabular}{|c|c|c|c|c|c|}
\hline & \multirow[t]{2}{*}{$\%$} & \multirow[t]{2}{*}{$\mathrm{N}$} & \multicolumn{2}{|l|}{ Gun carrying } & \multirow[t]{2}{*}{$\chi^{2}$} \\
\hline & & & No $\%(n)$ & Yes \% (n) & \\
\hline Grade & & & & & 7.65 \\
\hline 9th Grade & 26.26 & 1,315 & $97.37 \%(1,265)$ & $2.63 \%(42)$ & \\
\hline 10th Grade & 25.22 & 1,290 & $97.33 \%(1,240)$ & $2.67 \%(38)$ & \\
\hline 11th Grade & 24.12 & 1,038 & $96.99 \%(992)$ & $3.01 \%(36)$ & \\
\hline 12th Grade & 24.40 & 1,014 & $95.61 \%(958)$ & $4.39 \%(50)$ & \\
\hline Race/ethnicity & & & & & $52.74 * * *$ \\
\hline White & 91.47 & 3,728 & $97.40 \%(3,607)$ & $2.60 \%(94)$ & \\
\hline Hispanic & 2.80 & 266 & $87.51 \%(232)$ & $12.49 \%(33)$ & \\
\hline Black & 1.72 & 163 & $91.34 \%(150)$ & $8.66 \%(13)$ & \\
\hline Asian & 1.32 & 120 & $94.17 \%(113)$ & $5.83 \%(7)$ & \\
\hline Multiple races \& other race/ethnicity & 2.69 & 266 & $94.30 \%(245)$ & $5.70 \%(15)$ & \\
\hline Sexual orientation & & & & & $81.69 * * *$ \\
\hline Straight & 91.04 & 4,215 & $97.55 \%(4,078)$ & $2.45 \%(107)$ & \\
\hline Sexual minority & 5.26 & 259 & $91.15 \%(223)$ & $8.85 \%(33)$ & \\
\hline Not Sure & 3.71 & 183 & $87.43 \%(154)$ & $12.57 \%(26)$ & \\
\hline Suicidal ideation in the past 12 months & & & & & $67.94 * * *$ \\
\hline No & 88.98 & 4,005 & $97.96 \%(3,892)$ & $2.04 \%(88)$ & \\
\hline Yes & 11.02 & 515 & $91.55 \%(464)$ & $8.45 \%(51)$ & \\
\hline Alcohol use in the past 30 days & & & & & $95.00 * * *$ \\
\hline 0 days & 76.29 & 3,183 & $99.05 \%(3,140)$ & $0.95 \%(31)$ & \\
\hline$\geq 1$ days & 23.71 & 946 & $93.81 \%(870)$ & $6.19 \%(63)$ & \\
\hline Marijuana use in the past 30 days & & & & & $81.71 * * *$ \\
\hline 0 times & 79.16 & 3,430 & $98.30 \%(3,352)$ & $1.70 \%(59)$ & \\
\hline$\geq 1$ times & 20.84 & 900 & $92.62 \%(813)$ & $7.38 \%(69)$ & \\
\hline Gun access & & & & & $60.32 * * *$ \\
\hline Hard & 54.57 & 2,564 & $98.71 \%(2,514)$ & $1.29 \%(39)$ & \\
\hline Easy & 45.43 & 2,069 & $94.72 \%(1,929)$ & $5.28 \%(124)$ & \\
\hline Gender-based bullying & & & & & $65.41 * * *$ \\
\hline No & 90.54 & 4,138 & $97.77 \%(4,010)$ & $2.23 \%(98)$ & \\
\hline Yes & 9.46 & 439 & $90.92 \%(389)$ & $9.08 \%(49)$ & \\
\hline Sexual orientation-based bullying & & & & & $82.12 * * *$ \\
\hline No & 92.99 & 4,258 & $97.71 \%(4,129)$ & $2.29 \%(102)$ & \\
\hline Yes & 7.01 & 339 & $88.84 \%(291)$ & $11.16 \%(46)$ & \\
\hline \multicolumn{6}{|l|}{ Gun carrying in the past year } \\
\hline 0 times & 96.73 & 4,494 & - & - & - \\
\hline$\geq 1$ time & 3.27 & 176 & - & - & - \\
\hline
\end{tabular}

sexual orientation, compared to those who did not, had significantly greater odds of reporting they carried a gun to school one or more times in the past year (OR 3.57, 95\% CI 1.91, 6.67, $p<.001)$ while controlling for grade level, race/ethnicity, sexual orientation, suicidal ideation, alcohol and marijuana use, and gun access.

\section{Discussion}

Research has consistently shown that being a victim and/ or perpetrator of bullying is a significant predictor of gun carrying among adolescents (Valdebenito et al., 2017; Van 
Table 2 Logistic regression analyses for gun carrying by independent variables and covariates

\begin{tabular}{|c|c|c|c|c|}
\hline \multirow[t]{2}{*}{ Gun Carrying (Ref. group: 0 times) } & \multicolumn{2}{|c|}{ Model $1 * * *$} & \multicolumn{2}{|c|}{ Model 2*** } \\
\hline & OR & $95 \% \mathrm{CI}$ & OR & $95 \% \mathrm{CI}$ \\
\hline \multicolumn{5}{|l|}{ Grade } \\
\hline 9th grade & Ref & Ref & Ref & Ref \\
\hline 10th grade & .91 & {$[.39,2.12]$} & .78 & {$[.34,1.79]$} \\
\hline 11th grade & 1.15 & {$[.52,2.58]$} & 1.03 & {$[.48,2.23]$} \\
\hline 12th grade & 1.36 & {$[.64,2.88]$} & 1.19 & {$[.57,2.46]$} \\
\hline \multicolumn{5}{|l|}{ Race/ethnicity } \\
\hline White & Ref & Ref & Ref & Ref \\
\hline Hispanic & 1.75 & {$[.85,3.61]$} & 1.70 & {$[.83,3.50]$} \\
\hline Black & 2.76 & {$[.96,7.93]$} & 2.59 & {$[.92,7.26]$} \\
\hline Asian & .99 & {$[.13,7.65]$} & .80 & {$[.10,6.32]$} \\
\hline Multiple races \& other race/ethnicity & 1.31 & {$[.50,3.44]$} & 1.23 & {$[.48,3.15]$} \\
\hline \multicolumn{5}{|l|}{ Sexual orientation } \\
\hline Straight & Ref & Ref & Ref & Ref \\
\hline Sexual minority & .55 & {$[.24,1.28]$} & .55 & {$[.22,1.37]$} \\
\hline Not sure & $2.35 *$ & {$[1.00,5.51]$} & $2.33 *$ & {$[1.03,5.27]$} \\
\hline \multicolumn{5}{|l|}{ Suicidal ideation in the past 12 months } \\
\hline No & Ref & Ref & Ref & Ref \\
\hline Yes & $2.09 *$ & {$[1.14,3.83]$} & $2.17 * *$ & {$[1.25,3.77]$} \\
\hline \multicolumn{5}{|l|}{ Alcohol use in the past 30 days } \\
\hline 0 Days & Ref & Ref & Ref & Ref \\
\hline$\geq 1$ Days & $3.27 * * *$ & {$[1.80,5.95]$} & $3.31 * * *$ & {$[1.84,5.96]$} \\
\hline \multicolumn{5}{|l|}{ Marijuana use in the past 30 days } \\
\hline 0 times & Ref & Ref & Ref & Ref \\
\hline$\geq 1$ times & 1.78 & {$[.99,3.20]$} & $1.82 *$ & {$[1.02,3.23]$} \\
\hline \multicolumn{5}{|l|}{ Gun access } \\
\hline Hard & Ref & Ref & Ref & Ref \\
\hline Easy & $2.27 * *$ & {$[1.29,3.98]$} & $2.03 *$ & {$[1.87,3.49]$} \\
\hline \multicolumn{5}{|l|}{ Gender-based bullying } \\
\hline No & Ref & Ref & - & - \\
\hline Yes & $3.40 * * *$ & {$[1.64,5.62]$} & - & - \\
\hline \multicolumn{5}{|l|}{ Sexual orientation-based bullying } \\
\hline No & & & Ref & Ref \\
\hline Yes & & & $3.57 * * *$ & {$[1.91,6.67]$} \\
\hline \multicolumn{5}{|l|}{$O R$ odds ratio, $C I$ confidence interval } \\
\hline \multicolumn{5}{|l|}{ Model 1: $n=3683$} \\
\hline \multicolumn{5}{|l|}{ Model 2: $n=3707$} \\
\hline \multicolumn{5}{|l|}{$* p<.05$} \\
\hline \multicolumn{5}{|l|}{$* * p<.01$} \\
\hline$* * * p<.001$ & & & & \\
\hline
\end{tabular}

Geel et al., 2014). Despite this connection, there remains little known about the type of the bullying that may influence this relationship. This study found that high school boys who reported experiencing bullying victimization based on either gender or sexual orientation had significantly greater odds (threefold) of reporting they carried a gun to school one or more times in the past year. This confirms the two hypotheses of this study. These results may provide further evidence that bullying victims may use gun carrying as a means of self-protection, which is posited by the "vulnerability/self-protection hypothesis" (Valdebenito et al., 2017, p. 63).

Previous research has shown that there is an increase in frequency of bullying using homophobic epithets as boys move through high school (Poteat, O’Dwyer, \& Mereish, 2012). This may be a result of masculine socialization and gendered cultural norms (Poteat et al., 2012) that maintain attitudes of homophobia (Birkett \& Espelage, 2015), 
toughness, and emotional stoicism (Levant et al., 1992). Given these masculine and homophobic socialization norms, it may be that high school boys who experience bullying victimization based on gender or sexual orientation perceive the greatest threat from their peers; therefore, they carry a gun to school as a self-protective measure and an act of toughness.

Overall, this study found that over $3 \%$ of the sample reported carrying a gun to school one or more times in the previous year, which is equivalent to previously reported rates of weapon carrying (e.g. gun, knife, or club) on school property in nationally representative data (Kann et al., 2018) and slightly less than general rates of handgun carrying among adolescent boys 12-17 years old (Vaughn et al., 2016). Among the sample, nearly $10 \%$ reported experiencing bullying victimization based on gender, while 7\% reported experiencing bullying victimization based on sexual orientation.

Not surprisingly, this study found that high school boys who reported having "easy" access to a gun had greater odds of reporting they carried a gun to school. Previous research has shown that adolescents who have been bullied, either via traditional bullying and/or cyberbullying methods, were more likely to report access to a gun without adult permission (Simckes et al., 2017). This prior research, in conjunction with our findings, show that gun access (Brent et al., 1991; Grossman et al., 2005), gun carrying (Muula et al., 2008), and bullying victimization (Arseneault et al., 2010) are associated with suicidal ideation among adolescents. Furthermore, gun access alone can also increase the risk of gun-related crime (Pickett et al., 2005) and suicide (Shah, Hoffman, Wake, \& Marine, 2000) among adolescents. The results from this study also found that suicidal ideation is associated with carrying a gun to school. Bullying negatively impacts the emotional and psychological health of victims (Arseneault et al., 2010). These changes may increase the perceived vulnerability of the bullying victim, further leading to gun carrying as a protective measure. Similarly, alcohol use was significantly associated with carrying a gun to school. This finding is supported by previous research showing an association between substance use and weapon carrying (Stickley et al., 2015); however, the lack of significance of marijuana use is surprising given the overall high prevalence rates of marijuana use among adolescents (Miech, Johnston, \& O’Malley, 2017).

Sexual orientation was uniquely associated with gun carrying among the sample in this study. High school boys who were "unsure" of their sexual orientation had significantly greater odds of reporting they carried a gun to school compared to "heterosexual (straight)" boys. It may be that high school boys who are "unsure" of their sexual orientation are more negatively impacted psychologically, emotionally, and socially by bullying victimization based on gender or sexual orientation given their uncertain sexuality. Therefore, they may be more likely to seek gun carrying for self-protection and/or to protect their masculinity within the social context. Arguably, these high school boys fall within the category of being a sexual minority, as they do not identify within the usual binary sexual orientation categories. If this is the case, it may be that these boys experience more bullying victimization compared to their heterosexual peers, which has been confirmed by previous research (Berlan, Corliss, Field, Goodman, \& Austin, 2010; Toomey \& Russell, 2016).

The results from this study provide important support for two of the Grand Challenges for Social Work: building healthy relationships to end violence and ensuring the healthy development for all youth (Fong, Lubben, \& Barth, 2017). Social workers and school personnel should consider bullying based on gender and sexual orientation a significant risk factor for gun carrying and potential school violence given that 13 out of 15 school shootings analyzed between 1995 and 2001 included bullying (Leary, Kowalski, Smith, \& Phillips, 2003). Therefore, in order to address these Grand Challenges, school-based interventions aimed at decreasing bullying victimization, specifically bullying based on gender and sexual orientation, are warranted. Potential interventions may include the implementation and strengthening of inclusive curricula (Snapp, McGuire, Sinclair, Gabrion, \& Russell, 2015) and student groups, such as Gay-Straight Alliances (GSA; Poteat, Sinclair, DiGiovanni, Koenig, \& Russell, 2013). These interventions may also begin to dismantle traditional norms of masculinity that are associated with poor outcomes, including school violence (Rocque, 2012). Additionally, social workers and school personnel should screen for bullying, gun access, and gun carrying, particularly among high school boys. Social workers can explore the type of bullying to help identify specific interventions to best support the adolescent, as well as prevent further risky behaviors (e.g. gun carrying at school, suicidal ideation, and alcohol use; Collier et al., 2013; Holt et al., 2015; Swearer et al., 2008). Lastly, it is imperative that public policies focus on reducing gun access among adolescents, including increasing safe storage of firearms and strengthening background checks, as well as focusing on the implementation of anti-bullying, positive youth development, and school safety initiatives.

\section{Limitations \& Implications for Future Research}

Despite the strengths of this study, there are limitations to be noted. Given that the sample is from a single state, the generalizability to the entire United States is limited. However, the rates of carrying a gun to school were similar to national rates of weapon carrying at school, indicating relevance of our findings. Similarly, the sample is comprised of predominantly White adolescents. While this is representative of Maine, the link between bullying victimization 
based on gender and sexual orientation among a diverse sample remains needed. This study used cross-sectional data; therefore, it is unknown whether the bullying victimization preceded the gun carrying, or vice versa. Additionally, the measures were based on self-report and could be subject to reporting bias. The gun carrying measure did not indicate whether students were permitted to bring the gun to school (e.g. for riflery practice) or if the students brought the gun to school but did not bring it into the building (e.g. left it in their car). The gender and sexual orientation bullying victimization measures were limited given that they are single item measures that do not examine the type of the bullying thoroughly and have not been widely used in previous analyses. Despite these limitations, to our knowledge, this is the first study to use these measures. Ultimately, this is a strength of the analysis. Additionally, these measures confound different bullying victimization experiences (e.g. verbal and physical attacks). Therefore, we are unable to extrapolate the effects of these unique experiences on gun carrying. Lastly, the MIYHS does not include a socioeconomic status variable or proxy variable. Therefore, this analysis was unable to control for this demographic factor. Future research should emphasize a longitudinal design to gain a greater understanding of the type of bullying victimization that leads to gun carrying among adolescents, as well as include a nationally representative sample. Given our findings, it is important to investigate how these bullying measures interact to gain an expanded understanding of their relationship with gun carrying.

\section{Conclusion}

This study aimed to identify the specific type of bullying victimization that is associated with carrying a gun to school among a sample of high school boys. Results indicated that high school boys who experienced bullying victimization based on both gender and sexual orientation, compared to those who experienced neither form of bulling victimization, had significantly greater odds of reporting they carried a gun to school at least one time in the past year, while controlling for demographic characteristics and covariates. These results provide a unique understanding of the specific type of bullying victimization that may lead to gun carrying on school grounds among high school boys. This further emphasizes the need for strengthening bullying prevention efforts, expanding positive youth development programming, and restricting gun access in order to reduce gun carrying and potential gun violence.

Acknowledgements We would like to thank Sam Benabou for providing editorial assistance. This study was accepted for presentation at the Society for Adolescent Health and Medicine March 2020 Annual
Meeting, however, was not presented as the conference was cancelled due to the COVID-19 pandemic. The abstract was published in the Journal of Adolescent Health volume 66, issue 2, supplement, S29-S30. https://doi.org/10.1016/j.jadohealth.2019.11.058.

Author Contributions KTG conceived of the study, conducted the analysis, and drafted the manuscript. JMN provided consultation on the study design and statistical analysis, as well as drafting and editing the manuscript. Both KTG and JMN approved the final version of the manuscript.

Funding No funding was used for this study.

Data Availability Information on how to obtain the Maine Integrated Youth Health Survey (MIYHS) is available on the Maine Department of Public Health website (https://data.mainepublichealth.gov/miyhs/ home).

\section{Compliance with Ethical Standards}

Conflict of interest The authors declare no conflicts of interest.

Ethics Approval This study was approved by the Simmons University Institutional Review Board.

Informed Consent Participant consent is gathered from parents or guardians via a passive, opt-out consent procedure. See the Maine Department of Health and Human Services for more information on the MIYHS consent procedures: https://data.mainepublichealth.gov/ miyhs/home

\section{References}

Anagnostopoulos, D., Buchanan, N. T., Pereira, C., \& Lichty, L. F. (2009). School staff responses to gender-based bullying as moral interpretation: An exploratory study. Educational Policy, 23(4), 519-553. https://doi.org/10.1177/0895904807312469.

Arseneault, L., Bowes, L., \& Shakoor, S. (2010). Bullying victimization in youths and mental health problems: 'Much ado about nothing'? Psychological Medicine, 40(5), 717-729. https://doi. org/10.1017/s0033291709991383.

Berlan, E. D., Corliss, H. L., Field, A. E., Goodman, E., \& Austin, S. B. (2010). Sexual orientation and bullying among adolescents in the Growing Up Today Study. Journal of Adolescent Health, 46(4), 366-371. https://doi.org/10.1016/j.jadohealth.2009.10.015.

Birkett, M., \& Espelage, D. L. (2015). Homophobic name-calling, peergroups, and masculinity: The socialization of homophobic behavior in adolescents. Social Development, 24(1), 184-205. https:// doi.org/10.1111/sode.12085.

Birkett, M., Espelage, D. L., \& Koenig, B. W. (2009). LGB and questioning students in schools: The moderating effects of homophobic bullying and school climate on negative outcomes. Journal of Youth and Adolescence, 38(7), 989-1000. https://doi.org/10.1007/ s10964-008-9389-1.

Brent, D. A., Perper, J. A., Allman, C. J., Moritz, G. M., Wartella, M. E., \& Zelenak, J. P. (1991). The presence and accessibility of firearms in the homes of adolescent suicides: A case-control study. JAMA, 266(21), 2989-2995. https://doi.org/10.1001/ jama.1991.03470210057032.

Brown, B. (2004). Juveniles and weapons: Recent research, conceptual considerations, and programmatic interventions. Youth 
Violence and Juvenile Justice, 2(2), 161-184. https://doi. org/10.1177/1541204003262226.

Carlyle, K. E., \& Steinman, K. J. (2007). Demographic differences in the prevalence, co-occurrence, and correlates of adolescent bullying at school. Journal of School Health, 77(9), 623-629. https ://doi.org/10.1111/j.1746-1561.2007.00242.x.

Centers for Disease Control and Prevention (CDC). (2015). YRBS National, State, and District Combined Datasets User's Guide. Retrieved September 1, 2019, from https://www.cdc.gov/healt hyyouth/data/yrbs/pdf/2015/2015_yrbs_sadc_documentation.pdf.

Centers for Disease Control and Prevention (CDC). (2019). National Center for Injury Prevention and Control. Web-based Injury Statistics Query and Reporting System (WISQARS). Retrieved June 25, 2019, from www.cdc.gov/injury/wisqars.

Collier, K. L., Van Beusekom, G., Bos, H. M., \& Sandfort, T. G. (2013). Sexual orientation and gender identity/expression related peer victimization in adolescence: A systematic review of associated psychosocial and health outcomes. Journal of Sex Research, 50(3-4), 299-317. https://doi.org/10.1080/00224499.2012.75063 9.

Dukes, R. L., Stein, J. A., \& Zane, J. I. (2010). Gender differences in the relative impact of physical and relational bullying on adolescent injury and weapon carrying. Journal of School Psychology, 48(6), 511-532. https://doi.org/10.1016/j.jsp.2010.08.001.

Esselmont, C. (2014). Carrying a weapon to school: The roles of bullying victimization and perceived safety. Deviant Behavior, 35(3), 215-232. https://doi.org/10.1080/01639625.2013.834767.

Fong, R., Lubben, J., \& Barth, R. P. (Eds.). (2017). Grand challenges for social work and society. Oxford: Oxford University Press.

Fox, J. A., \& DeLateur, M. J. (2014). Mass shootings in America: Moving beyond Newtown. Homicide Studies, 18(1), 125-145.

Grossman, D. C., Mueller, B. A., Riedy, C., Dowd, M. D., Villaveces, A., Prodzinski, J., et al. (2005). Gun storage practices and risk of youth suicide and unintentional firearm injuries. JAMA, 293(6), 707-714. https://doi.org/10.1001/jama.293.6.707.

Holt, M. K., Vivolo-Kantor, A. M., Polanin, J. R., Holland, K. M., DeGue, S., Matjasko, J. L., ... Wolfe, M. (2015). Bullying and suicidal ideation and behaviors: A meta-analysis. Pediatrics, 135(2), e496-e509. https://doi.org/10.1542/peds.2014-1864.

Johnson, D., \& Barsky, A. E. (2020). Preventing gun violence in schools: Roles and perspectives of social workers. School Social Work Journal, 44(2), 26-48.

Kalesan, B., Lagast, K., Villarreal, M., Pino, E., Fagan, J., \& Galea, S. (2017). School shootings during 2013-2015 in the USA. Injury Prevention, 23(5), 321-327. https://doi.org/10.1136/injuryprev -2016-042162.

Kann, L., McManus, T., Harris, W. A., Shanklin, S. L., Flint, K. H., Queen, B., ... Ethier, K. A. (2018). Youth risk behavior surveillance - United States, 2017. Morbidity and Mortality Weekly Report Surveillance Summaries, 67(8), 1-114.

Leary, M. R., Kowalski, R. M., Smith, L., \& Phillips, S. (2003). Teasing, rejection, and violence: Case studies of the school shootings. Aggressive Behavior, 29(3), 202-214. https://doi.org/10.1002/ ab.10061.

Levant, R. F., Hirsch, L. S., Celentano, E., Cozza, T. M., et al. (1992). The male role: An investigation of contemporary norms. Journal of Mental Health Counseling, 14(3), 325-337. https://psycnet.apa. org/record/1993-00044-001.

Livingston, M. D., Rossheim, M. E., \& Hall, K. S. (2019). A descriptive analysis of school and school shooter characteristics and the severity of school shootings in the United States, 1999-2018. Journal of Adolescent Health, 64(6), 797-799. https://doi. org/10.1016/j.jadohealth.2018.12.006.

Maine Department of Health and Human Services. Maine Integrated Youth Health Survey. Retrieved June 30, 2019, from https://data. mainepublichealth.gov/miyhs/home.
Menesini, E., \& Salmivalli, C. (2017). Bullying in schools: The state of knowledge and effective interventions. Psychology, Health \& Medicine, 22(sup1), 240-253. https://doi.org/10.1080/13548 506.2017.1279740.

Miech, R., Johnston, L., \& O’Malley, P. M. (2017). Prevalence and attitudes regarding marijuana use among adolescents over the past decade. Pediatrics. https://doi.org/10.1542/peds.2017-0982.

Modecki, K. L., Minchin, J., Harbaugh, A. G., Guerra, N. G., \& Runions, K. C. (2014). Bullying prevalence across contexts: A meta-analysis measuring cyber and traditional bullying. Journal of Adolescent Health, 55(5), 602-611. https://doi.org/10.1016/j. jadohealth.2014.06.007.

Muula, A. S., Rudatsikira, E., \& Siziya, S. (2008). Correlates of weapon carrying among high school students in the United States. Annals of General Psychiatry, 7, 1-8. https://doi. org/10.1186/1744-859X-7-8.

Pham, T. B., Schapiro, L. E., John, M., \& Adesman, A. (2017). Weapon carrying among victims of bullying. Pediatrics, 140(6), e20170353. https://doi.org/10.1542/peds.2017-0353.

Pickett, W., Craig, W., Harel, Y., Cunningham, J., Simpson, K., Molcho, M., ... HBSC Violence and Injuries Writing Group. (2005). Cross-national study of fighting and weapon carrying as determinants of adolescent injury. Pediatrics, 116(6), e855-e863. https:// doi.org/10.1542/peds.2005-0607

Poteat, V. P., O'Dwyer, L. M., \& Mereish, E. H. (2012). Changes in how students use and are called homophobic epithets over time: Patterns predicted by gender, bullying, and victimization status. Journal of Educational Psychology, 104(2), 393.

Poteat, V. P., Sinclair, K. O., DiGiovanni, C. D., Koenig, B. W., \& Russell, S. T. (2013). Gay-straight alliances are associated with student health: A multischool comparison of LGBTQ and heterosexual youth. Journal of Research on Adolescence, 23(2), 319-330. https://doi.org/10.1111/j.1532-7795.2012.00832.x.

Rocque, M. (2012). Exploring school rampage shootings: Research, theory, and policy. The Social Science Journal, 49(3), 304-313. https://doi.org/10.1016/j.soscij.2011.11.001.

Romero, A., Bauman, S., Ritter, M., \& Anand, P. (2017). Examining adolescent suicidal behaviors in relation to gun carrying and bullying. Journal of School Violence, 16(4), 445-458. https://doi. org/10.1080/15388220.2016.1190933.

Schapiro, L. E., John, M., \& Adesman, A. (2014). Association between victims of bullying and weapon carrying among high school students in the United States. Journal of Adolescent Health, 54(2), S43. https://doi.org/10.1016/j.jadohealth.2013.10.099.

Shah, S., Hoffman, R. E., Wake, L., \& Marine, W. M. (2000). Adolescent suicide and household access to firearms in Colorado: Results of a case-control study. Journal of Adolescent Health, 26(3), 157-163. https://doi.org/10.1016/S1054-139X(99)00064-6.

Simckes, M. S., Simonetti, J. A., Moreno, M. A., Rivara, F. P., Oudekerk, B. A., \& Rowhani-Rahbar, A. (2017). Access to a loaded gun without adult permission and school-based bullying. Journal of Adolescent Health, 61(3), 329-334. https://doi.org/10.1016/j. jadohealth.2017.03.022.

Snapp, S. D., McGuire, J. K., Sinclair, K. O., Gabrion, K., \& Russell, S. T. (2015). LGBTQ-inclusive curricula: Why supportive curricula matter. Sex Education, 15(6), 580-596. https://doi. org/10.1080/14681811.2015.1042573.

StataCorp. (2017). Stata Statistical Software: Release 15. College Station, TX: StataCorp LLC.

Stickley, A., Koyanagi, A., Koposov, R., Blatný, M., Hrdlička, M., Schwab-Stone, M., Ruchkin, V. (2015). Correlates of weapon carrying in school among adolescents in three countries. American Journal of Health Behavior, 39(1), 99-108. https://doi. org/10.5993/AJHB.39.1.11.

Swearer, S. M., Turner, R. K., Givens, J. E., \& Pollack, W. S. (2008). "You're so gay!": Do different forms of bullying matter for 
adolescent males? School Psychology Review, 37(2), 160-173. https://doi.org/10.1080/02796015.2008.12087891.

Toomey, R. B., \& Russell, S. T. (2016). The role of sexual orientation in school-based victimization: A meta-analysis. Youth \& Society, 48(2), 176-201.

Valdebenito, S., Ttofi, M. M., Eisner, M., \& Gaffney, H. (2017). Weapon carrying in and out of school among pure bullies, pure victims and bully-victims: A systematic review and meta-analysis of cross-sectional and longitudinal studies. Aggression and Violent Behavior, 33, 62-77. https://doi.org/10.1016/j.avb.2017.01.004.

van Geel, M., Vedder, P., \& Tanilon, J. (2014). Bullying and weapon carrying: A meta-analysis. JAMA Pediatrics, 168(8), 714-720. https://doi.org/10.1001/jamapediatrics.2014.213.

Vaughn, M. G., Nelson, E. J., Salas-Wright, C. P., DeLisi, M., \& Qian, Z. (2016). Handgun carrying among White youth increasing in the United States: New evidence from the National Survey on Drug Use and Health 2002-2013. Preventive Medicine, 88, 127-133. https://doi.org/10.1016/j.ypmed.2016.03.024.

Vaughn, M. G., Perron, B. E., Abdon, A., Olate, R., Groom, R., \& Wu, L. T. (2012). Correlates of handgun carrying among adolescents in the United States. Journal of Interpersonal Violence, 27(10), 2003-2021.

Vivolo-Kantor, A. M., Martell, B. N., Holland, K. M., \& Westby, R. (2014). A systematic review and content analysis of bullying and cyber-bullying measurement strategies. Aggression and Violent Behavior, 19(4), 423-434. https://doi.org/10.1016/j. avb.2014.06.008.

Wilkinson, D. L., \& Fagan, J. (2001). What we know about gun use among adolescents. Clinical Child and Family Psychology Review, 4(2), 109-132. https://doi.org/10.1023/A:1011329130 712.

Publisher's Note Springer Nature remains neutral with regard to jurisdictional claims in published maps and institutional affiliations. 